\title{
SAN XoÁn de VILANOVA Y LA CUESTIÓN LOMBARDISTA
}

\author{
SAN XoÁn de VILANOVA E A QUESTÃo lOMBARDISTA
}

SAN XOÁN DE VILANOVA AND THE LOMBARDIST QUESTION

\author{
Javier Castiñeiras López* \\ javier.castineiras84@gmail.com
}

ResUmen: La iglesia de San Xoán de Vilanova (Miño, A Coruña, Galicia) destaca en el conjunto del patrimonio románico del noroeste de la Península Ibérica, al ser una de las pocas muestras en la región de una arquitectura que emplea un lenguaje edilicio vinculable a la tradición lombardista. Con el presente trabajo se abordará esta problemática cuestión historiográfica y se procederá al estudio del templo en relación a su contexto monumental, con el objetivo de poder establecer cuáles fueron los modelos y quiénes los actores que pudieron propiciar la aparición de unas formas a priori ajenas a la tradición constructiva de los reinos hispanos occidentales.

PalabRAS ClAVE: Arquitectura Románica, Arquitectura Lombardista, San Xoán de Vilanova.

RESUMO: A igreja de São João de Vilanova (Minho, A Corunha, Galiza) se destaca no conjunto do patrimônio românico do noroeste da Península lbérica, ao ser uma das poucas mostras na região de uma arquitetura que emprega uma linguagem construtiva em relação à tradição lombardista. Com o presente trabalho se estuda esta problemática questão historiográfica e se analisa o templo em relação ao seu contexto monumental, com o objetivo de poder estabelecer quais são os modelos e quem foram os atores que puderam propiciar o aparecimento de formas a priori alheias à tradição construtiva dos reinos hispânicos ocidentais.

PALAVRAS CHAVE: Arquitetura Românica, Arquitetura Lombardista, São João de Vilanova.

ABSTRACT: The church of San Xoán de Vilanova (Miño, A Coruña, Galicia) stands out in the Romanesque heritage of the northwest of the Iberian Peninsula, because it is one of the few examples in the region of an architecture that uses a Lombardist constructive language. With the present work we will analyze this historiographical question and we will study the temple in relation to the monumental context, with the objective of knowing which were the models and who were the actors that could promote the presence of unknown forms in the constructive tradition of the western Hispanic kingdoms.

KEYWORDS: Romanesque Architecture, Lombard Architecture, San Xoán de Vilanova.

\section{Introducción}

En el año 2001, en la ciudad italiana de Parma, se celebraron unas jornadas destinadas a llevar los estudios sobre el románico lombardo a la realidad historiográfica de los inicios del siglo XXI. Aunque el grueso de estas se centró en el arte románico italiano, algunas de las sesiones abordaron el fenómeno en otros territorios europeos. Como parte de este segundo grupo, Castiñeiras González se ocupó de los procesos de creación en los inicios del

\footnotetext{
* Doctor en História por la Universidade de Santiago de Compostela. Profesor Departamento de Patrimonio Artístico y Documental, Universidad de León, León, España.
} 
románico en el territorio de Galicia $^{1}$, proponiendo dos vías principales: el arte francés vinculado a las peregrinaciones jacobeas y el primer románico o románico lombardista (CASTIÑEIRAS GONZÁLEZ, 2004, 602-613). El investigador hizo notar en su estudio que el peso -absolutamente justificado- de la catedral de Santiago de Compostela y sus vínculos con el románico de la Francia meridional han condicionado la mirada historiográfica sobre el románico gallego, ocultando en cierta medida la existencia de una segunda vía, la lombardista, en la que el autor incluye San Martiño de Mondoñedo, San Antoíño de Toques y San Xoán de Vilanova. De este último templo nos ocuparemos a continuación.

\section{San Xoán de Vilanova}

La iglesia de San Xoán de Vilanova es una pequeña construcción que se encuentra en el ayuntamiento de Miño, al norte de la provincia gallega de A Coruña. La única noticia conservada en la documentación medieval sobre esta capilla se recoge en la bula del papa Adriano IV de 1156, donde se incluye a San Xoán de Vilanova entre los principales monasterios de la diócesis de Mondoñedo, junto a los de San Martiño de Xuvia, San Salvador de Pedroso, San Martiño de Neda y Santiago de Silva (FLÓREZ, 1764, p. 350). La Bula papal nos informa acerca de la naturaleza monástica de la iglesia y nos proporciona la fecha de 1156 como terminus post quem para su construcción. Sin embargo, nada sabemos acerca de su fundación, ni tampoco sobre el restante devenir histórico del monasterio durante los siglos del Medievo ${ }^{2}$. Una última información, que trasciende ya los límites cronológicos de la Edad Media, la proporciona el cardenal Jerónimo del Hoyo (HOYO, 1607, p. 308), quien indica que

\footnotetext{
${ }^{1}$ Debe subrayarse que, desde finales de la dictadura en España en el año 1975, han surgido un importante número de estudios que abordan los diferentes fenómenos artísticos históricos desde unas coordenadas geográficas vinculadas al contemporáneo estado de las autonomías. Por ello, cuando se emplean los términos románico aragonés, románico catalán o románico gallego, estos generalmente se encajan en las actuales divisiones administrativas y no en la realidad geográfica del momento a estudiar. Téngase presente en cualquier caso que el Reino de Galicia es una realidad nominal en los tiempos del románico, si bien su extensión no era la actual, al alcanzar sus límites parte de los presentes territorios de Portugal y de León.

2 Ha sido propuesta como hipótesis que esta parquedad de menciones documentales pueda ser debida a la vinculación de Vilanova con otras parroquias de mayor enjundia, como San Pedro de Perbes y Santa María de Castro, y con los cotos jurisdiccionales de Breamo, Miño y Andrade (POUSA FERNÁNDEZ, 2013, p. 1263). Sin descartar esta posibilidad, el hecho de que en la Bula se incluya a Vilanova en la nómina de monasterios relevantes de la diócesis mindoniense debilita el argumento de la insignificancia institucional. Las propias innovaciones de su arquitectura parecen indicar incluso una cierta relevancia del monasterio en el momento de su construcción. Además, la ausencia de documentación medieval en Galicia no es ni mucho menos excepcional y son abundantes los ejemplos de construcciones románicas importantes en el territorio que apenas han dejado huella en las fuentes. Para Chamoso Lamas la iglesia pudo pertenecer a San Martiño Pinario desde su fundación en tiempos del abad Adulfo de San Martiño, pero es este un supuesto no documentado (CHAMOSO LAMAS, 1971, p. 272).
} 
parte de los frutos de la iglesia iban destinados al monasterio de Caión y que la presentación era de San Martiño Pinario de Santiago. Este silencio casi total de las fuentes escritas limita el estudio de San Xoán de Vilanova y deja como prácticamente único recurso metodológico el análisis de los vestigios materiales, el posterior estudio comparativo de su arquitectura y, finalmente, la exploración del contexto político y cultural en tanto que posible generador de las elecciones arquitectónicas.

Por su parte, la tradición historiográfica tampoco ha sido especialmente prolija y es escasa la nómina de estudios que se han ocupado de Vilanova, casi todos ellos además en publicaciones de carácter más amplio sobre el desarrollo del románico inicial en tierras gallegas. Sin ánimo de ser exhaustivos y ante los imponderables del espacio en un trabajo de estas características, las publicaciones más relevantes para elaborar un estado de la cuestión son las debidas a Chamoso Lamas (CHAMOSO LAMAS, 1971, 272-276. CHAMOSO LAMAS, 1973, 215-221. CHAMOSO LAMAS, GONZÁLEZ, REGAL, 1979, p. 39-43, 53, 62), Regal (REGAL, 1989, p. 25-67), Bango Torviso (BANGO TORVISO, 1987, p. 26, 31-33. BANGO TORVISO, 2001, p. 15), Valle Pérez (VALLE PÉREZ, 1984, p. 291-326), Yzquierdo Perrín (YZQUIERDO PERRíN, 1995, p. 168-170. YZQUIERDO PERRÍN, 2013, p. 207-243), Carrillo Lista (CARRILLO LISTA, 2005, 149-155) y Castiñeiras González (CASTIÑEIRAS GONZÁLEZ, 2004, p. 602-613). En el conjunto de estas investigaciones destacan especialmente dos cuestiones, la importancia concedida a la decoración externa del ábside y el desacuerdo a la hora de establecer una cronología relativa para la elevación de la fábrica, oscilando las propuestas entre mediados del siglo XI e inicios del siglo XII.

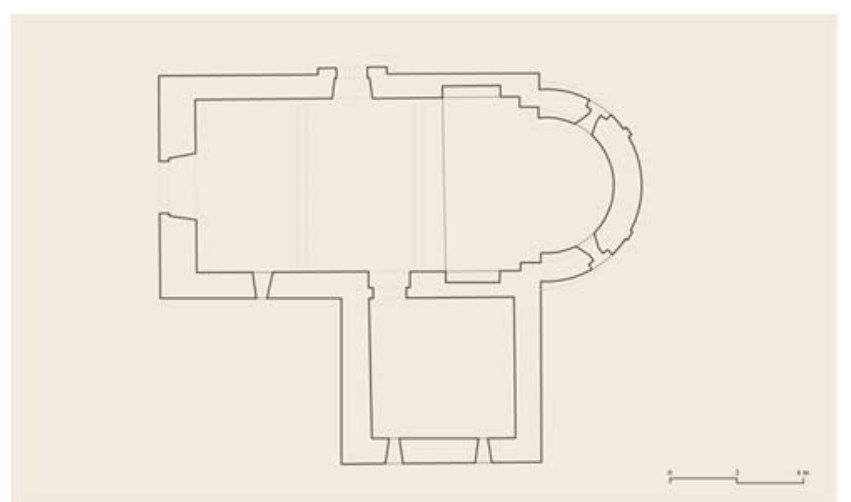

Figura 1: Planta de San Xoán de Vilanova. Iglesia de San Xoán (Vilanova) ㄷ Fundación Santa María la Real. Gumersindo Freire 
Iniciando ya el análisis de su arquitectura, el primer aspecto destacable es el relativamente buen estado de conservación de su fábrica románica, si bien en ella se realizaron a finales del siglo XVIII una serie de modificaciones importantes como el añadido de una sacristía abierta en el muro sur de la nave, la creación de nuevos vanos en el muro norte y la construcción de una nueva fachada con espadaña (SORALUCE BLOND, 1983, p. 81). A pesar de estas obras de época moderna, no se ha alterado demasiado la espacialidad de una construcción románica que, en planta, presenta nave única rematada por un ábside semicircular, precedido de un mínimo tramo recto y con bóveda de horno (Figura 1). Este modo de resolver la cabecera es doblemente innovador para la arquitectura románica de la región ya que, por un lado, se opta por el hemiciclo frente al más habitual testero recto, mientras que, además, la ausencia de columnas en el arco triunfal y su propia anchura crean una mayor integración entre los espacios del ábside y de la nave. Tanto el uso del testero semicircular como la integración espacial son características que se alejan de los tradicionales modos heredados de la arquitectura prerrománica y cuya presencia puede responder a la paulatina sustitución, desde finales del siglo XI, de la vieja liturgia hispana en favor de la liturgia romana (NÚÑEZ RODRÍGUEZ, 1983, p. 116). La importancia de esta innovación planimétrica es tal que, si como plantea Yzquierdo Perrín en sus diversos trabajos, este ábside se hubiese construido entre finales del siglo XI e inicios del siglo XII, nos encontraríamos ante un perfil de capilla absolutamente innovador, que solo contaría en Galicia con este ejemplo y el de las capillas de San Pedro y de San Juan en la catedral de Santiago de Compostela.

En su desarrollo exterior, la iglesia muestra nuevamente soluciones ajenas a los modos de la arquitectura precedente y más en sintonía con las fórmulas propias del primer románico. La curva del ábside se divide en tres tramos separados por pilastras a modo de lesenas que rematan en el inicio del friso de arquitos ciegos. Los arcos son de medio punto doblados y descansan sobre pequeñas ménsulas esculpidas con motivos vegetales, geométricos y cabezas humanas (Figura 2). Sobre estos se encuentra una cornisa conformada por hiladas de sillares decorados con un friso de tallos ondulantes ${ }^{3}$, similares a los que se emplean en los cimacios de San Martiño de Mondoñedo en la costa de Lugo hacia 1100 . Un último aspecto a destacar en la vista externa del hemiciclo es la alta calidad de su estereotomía

\footnotetext{
${ }^{3}$ También en las cornisas de los muros exteriores de la nave se encuentran piezas talladas con decoración relivaria (hojas, figuras, etc.) que se han puesto en relación con el arte prerrománico asturiano y que quizá pertenecieron a una construcción precedente (YZQUIERDO PERRÍN, 2013, p. 222).
} 
con unos sillares correctamente escuadrados, que atestiguan la presencia en Vilanova de un taller versado en esta nueva manera de concebir la arquitectura más que de unos artífices en proceso de ensayo de una nueva gramática edilicia.

\section{La arquitectura lombardista}

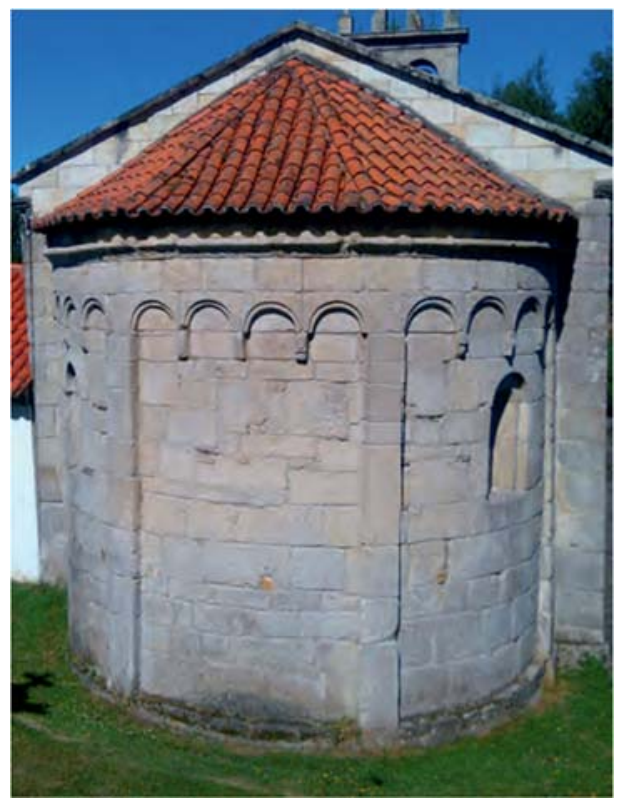

Figua 2: Ábside de San Xoán de Vilanova

Como se ha señalado en los párrafos iniciales, la manera de concebir la articulación del paramento exterior del ábside por medio de arquillos y lesenas, además de ser rupturista en el territorio de Galicia, se emparenta directamente con la arquitectura del primer románico, o románico lombardo, que tuvo un amplio desarrollo en Aragón, Cataluña, el sur de Francia y el norte de Italia a lo largo del siglo XI e, incluso, inicios del XII ${ }^{4}$. Dicha denominación, lejos de ser un mero calificativo terminológico, es uno de los conceptos más discutidos por los especialistas en la primera arquitectura románica y sitúa a la iglesia de San Xoán de Vilanova en el centro de una importante polémica historiográfica.

En la historiografía decimonónica ${ }^{5}$, el término lombardo se empleaba para referirse a los trabajos de una serie de talleres itinerantes -magistri comacini- que, en los inicios del siglo

\footnotetext{
${ }^{4}$ En el Inventario de la Riqueza Monumental de Galicia (CASTILLO LÓPEZ, 1987, p. 335) se utilizan los términos lombarda y catalana para referirse a esta arquitectura. La historiografía posterior ha utilizado estas denominaciones de manera habitual en relación con las formas empleadas en el exterior del ábside.

${ }^{5}$ Las referencias bibliográficas sobre este respecto son inabarcables para un artículo de estas características. En los últimos años se han realizado diversas jornadas científicas en las que se ha abordado el estudio de la arquitectura lombarda y en las que puede encontrase un completo estado de la cuestión (QUINTAVALLE (dir.), 2004. CAMPS, 2010; FREIXAS, 2010).
} 
$\mathrm{XI}$, ensayaron unas formas arquitectónicas innovadoras en las inmediaciones de los lagos de Como y Lugano, al norte de Italia, desde donde se irradiaron al sur de Francia y a los Condados Catalanes. Posteriormente, y gracias en gran medida al éxito historiográfico de las obras de autores como Porter (PORTER, 1915-1917) o Puig i Cadafalch (PUIG I CADAFALCH, 1930), el concepto trascendió su delimitación territorial original y pasó a utilizarse para casi todo el conjunto del primer románico. De este modo, lo lombardo se transformó en sinónimo de una arquitectura caracterizada, grosso modo, por el uso de un aparejo pequeño, lesenas, arquitos y por la ausencia de la escultura monumental que tanto desarrollo tendría con posterioridad durante el románico pleno. Puede apreciarse, por lo tanto, como la nomenclatura comenzó utilizándose en una parcela geográfica muy precisa, para acabar englobando un fenómeno edilicio común en el conjunto de la Europa Meridional.

En esencia, el centro de la polémica reside en el carácter étnico de estos maestros lombardos. En la génesis historiográfica del término lombardo se vinculaba directamente la aparición de las formas arquitectónicas con la presencia en obra de estos magistri comacini provenientes de los territorios norteños de la península itálica y que de manera itinerante recorrían los diversos territorios europeos. Frente a estas apreciaciones, se ha ido constatando a lo largo de los años la dificultad de rastrear a estos personajes en la documentación, lo que ha puesto en duda la necesaria relación entre los modos de la arquitectura del primer románico y la procedencia geográfica de sus artífices. Frente a los vacíos de información en las fuentes se va abriendo paso la pregunta de si toda la arquitectura lombarda debe ser atribuida a maestros de ascendencia lombarda y, con ella, se plantea un importante problema terminológico: ¿sigue siendo adecuado hablar de iglesias lombardas cuando no conozcamos nada de sus constructores? ¿la sola presencia de arquitos y lesenas es muestra de una uniformidad edilicia en la Europa del sur a inicios del románico?

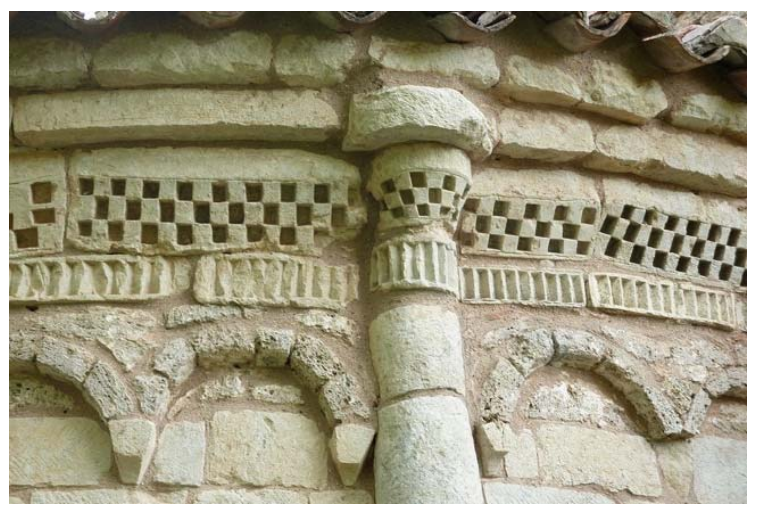


Figura 3: Arquitos ciegos de San Pelayo de

Perezancas (Foto: GFreihalter. Licencia

Como en cualquier polémica de carácter historiográfico y terminológico, las respuestas a estas cuestiones tienen múltiples aristas y resulta imposible abordar el conjunto del tema en un breve artículo como este. Si regresamos al caso que nos ocupa, la carencia de fuentes documentales acerca de la historia constructiva de San Xoán de Vilanova impide hablar de la presencia de maestros lombardos en el reino medieval de Galicia, pero además este supuesto es altamente improbable por la lejanía geográfica y por la inexistencia de menciones a estos personajes en otro tipo de documentación. Por ello, parece más adecuado para un edificio como Vilanova el sustituir el vocablo lombardo por el de lombardista, nomenclatura propuesta para algunos ejemplos del primer románico aragonés en los que, como en Vilanova, se constatan las formas, pero no la procedencia de los ejecutores de las mismas (ESTEBAN LORENTE; GALTIER MARTí; GARCÍA GUATAS, 1982, pp. 105-159).

\section{Antecedentes y modelos}

Al margen de los problemas terminológicos debe tenerse presente que, aunque la arquitectura lombardista no tiene en los reinos peninsulares occidentales el mismo desarrollo que en otros territorios hispanos y europeos, existen también algunas muestras significativas de este modo de concebir la arquitectura en dicha área geográfica. Se trata de una nómina muy reducida de construcciones que se desenvuelven en cronologías tardías, entre los años finales del siglo XI e inicios del siglo XII y que conviven con formulaciones que se acercan ya a los estándares del románico pleno ${ }^{6}$. Ejemplos de esta corriente lombardista occidental son las iglesias castellanoleonesas de Nuestra Señora de la Anunciada de Urueña (Valladolid) y San Pelayo de Perazancas (Palencia) junto a las gallegas San Martiño de Mondoñedo (Lugo) y San Antoíño de Toques (A Coruña). Son fábricas todas ellas de naturaleza diferente -tanto en volúmenes como en plantas- cuyo nexo común se encuentra en la utilización de los característicos arquitos bajo las cornisas de los ábsides. Es quizá la iglesia palentina la que presenta mayores similitudes con San Xoán de Vilanova (Figura 3), tanto en el modo de concebir los arquitos ciegos (BANGO TORVISO, 1987, p. 25) como como en la elección de un

\footnotetext{
${ }^{6}$ Estas afirmaciones son válidas de manera general, pero merecen unas pequeñas matizaciones. El uso del lenguaje lombardista en cronologías del románico pleno puede constatarse también en territorios más orientales como atestiguan los ejemplos de Taüll y Bagües. Además, es plausible que sean muchos los ejemplos de construcciones lombardistas en el occidente hispano que hoy se hayan perdido y que dibujasen un panorama mucho menos reducido del que se tiene en la actualidad.
} 
esquema planimétrico similar al del templo gallego, con una única nave rematada por un ábside semicircular y un pequeño tramo recto ${ }^{7}$.

Por otra parte, San Antoíño de Toques (a escasos 70 km de Vilanova) también se ha puesto en directa relación con la iglesia objeto de estudio por la presencia en el exterior de su ábside de una serie de pequeñas arcuaciones ciegas, pero un análisis detenido de ambas fábricas muestra más diferencias que similitudes. Aunque en plano ambas capillas desarrollan una planta con nave única y ábside, Vilanova se configura de un modo más complejo al emplear un perfil semicircular que propicia, además, una mayor integración espacial con el cuerpo de la nave al ser su arco triunfal casi del mismo ancho que esta. Frente a dichas innovaciones, en Toques se utiliza el testero recto en una capilla que funciona casi como un espacio autónomo y apenas dialoga con el cuerpo de la nave, siguiendo las inercias de los espacios estancos de la arquitectura altomedieval hispana. Exteriormente, es cierto que se constatan arquitos bajo el alero, pero estos apenas tienen entidad y se desenvuelven a modo de pequeño friso corrido sin continuación en bandas o lesenas, lo que lleva a pensar en una solución decorativa no estrictamente vinculable a la tradición lombardista (Figura 4). San Antoíño de Toques es, más que una fábrica del románico lombardista, un edificio cronológicamente románico -está documentada una donación del rey García de Galicia en 1067 (LUCAS ÁLVAREZ, 2001, p. 275-277)- pero en el que existen más pervivencias de la arquitectura precedente que innovaciones del nuevo lenguaje.

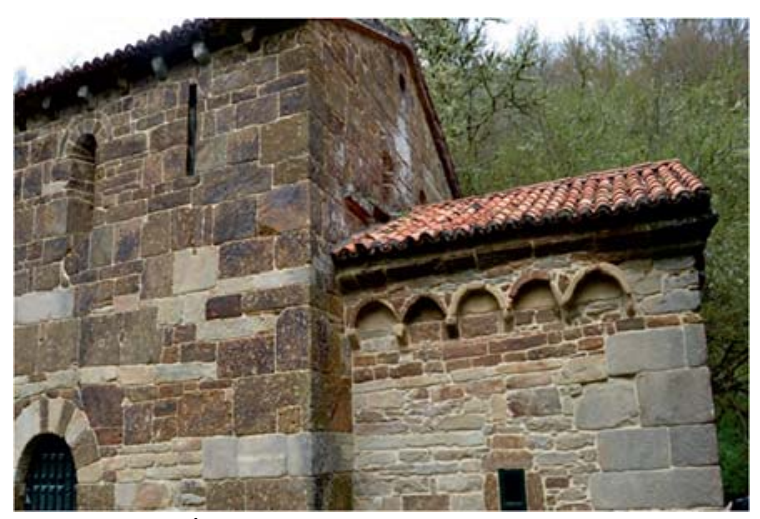

Figura 4: Ábside de San Antoíño de Toques

Además de en San Xoán de Vilanova, y una vez planteados los problemas de adscripción de San Antoíño de Toques, en tierras gallegas solamente en San Martiño de

\footnotetext{
${ }^{7}$ También se han propuesto para Vilanova los paralelos de Saint-Martin de Cazarilh, Notre-Dame de Trébons o San Fructuoso de Barós (CASTIÑEIRAS GONZÁLEZ, 2007, p. 124).
} 
Mondoñedo se pueden encontrar soluciones indiscutiblemente lombardistas. La antigua sede del obispado de Mondoñedo -aún siendo un edificio de mayores dimensiones y más complejo en planta con tres naves y tres ábsides- presenta muchas características que la emparentan con el edificio vilanovés. Así, en sus ábsides menores se desarrollan arquitos ciegos prolongados por lesenas de un modo comparable a los vistos y, en planta, a los hemiciclos mindonienses les preceden unos minúsculos y anchos tramos rectos que encuentran de nuevo paralelos en San Xoán de Vilanova (BANGO TORVISO, 1987, p. 26; YZQUIERDO PERRÍN, 1994, p. 32) y en San Pelayo de Perazancas. Esta manera tan excepcional de concebir la transición entre ábside y nave es un motivo de peso para plantear un posible trasvase directo de modelos entre estas edificaciones, o al menos la existencia de arquetipos comunes. Sin embargo, a pesar de estas importantes afinidades, el ábside de Vilanova presenta, en líneas generales, unos acabados más pulidos que los absidiolos mindonienses ${ }^{8}$. Mientras que en Mondoñedo se utiliza un único tramo de arcuaciones, el empleo de un aparejo de pequeñas dimensiones y arcos de perfil sencillo (Figura 5), el ábside de Vilanova se divide en tres tramos que emplean el mismo módulo de cuatro arquitos doblados y se configura con sillares regulares de mayores dimensiones. Con todas las precauciones, semeja que los artífices de Vilanova eran mejores conocedores de la técnica y ofrecen una capilla más afín al paradigma de lo lombardista

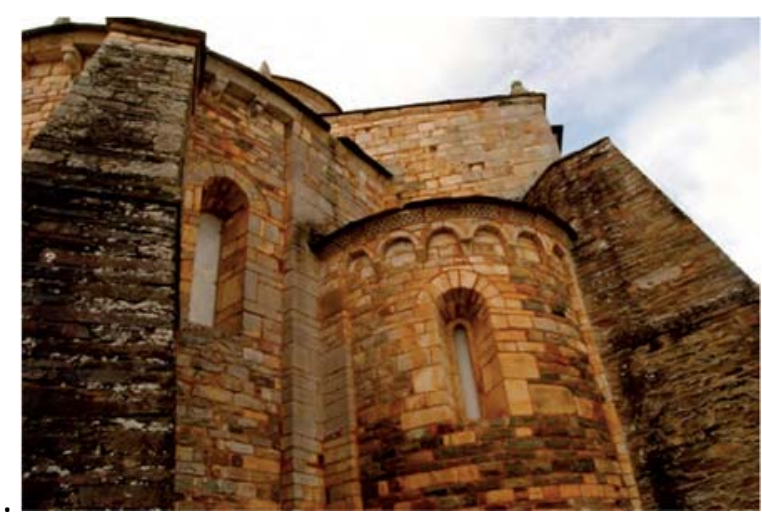

Figura 5: Absidiolo norte de San Martiño de Mondoñedo

Una vez trazado el posible mapa de relaciones, queda por plantear una datación relativa para San Xoán de Vilanova. Ya se ha indicado la ausencia de consenso, pero las últimas investigaciones se decantan por una construcción hacia 1100 en relación a las campañas

\footnotetext{
${ }^{8}$ Nos referimos en este trabajo únicamente a las diferencias entre los aspectos lombardistas de ambos edificios (concentrados en los ábsides), si bien estas son de mayor calado si atendemos a las fábricas al completo ya que, en Mondoñedo, se desarrollan aspectos propios del románico pleno que conviven con lo lombardista. También en Perazancas encontramos esta hibridación con la presencia de taqueado sobre los arquitos ciegos.
} 
auspiciadas por el obispo Gonzalo en San Martiño de Mondoñedo (CASTIÑEIRAS GONZÁLEZ, 1999. CASTIÑEIRAS GONZÁLEZ, 2004). Consideramos que la calidad de la estereotomía, la articulación modular de los arquitos y la brevedad del tramo recto acercan a Vilanova a modelos del primer románico pirenaico -más si cabe que Mondoñedo- lo que hace posible, incluso, una datación en el primer tercio del siglo XII, como una muestra tardía de la arquitectura lombardista peninsular en la línea de las catalano-aragonesas Taüll y Bagües.

\section{Recepción y patrocinio}

Una vez analizadas sucintamente las características de esta arquitectura y planteados algunos de los posibles paralelos, resta cuestionarse cómo fue el proceso de recepción de estas formas en el occidente peninsular y quiénes fueron los agentes que pudieron propiciarla.

Ya se ha hecho notar anteriormente que la arquitectura lombardista aparece en el occidente hispano en cronologías mucho más tardías que en latitudes más orientales. Los motivos no son bien conocidos ${ }^{9}$, pero se ha incidido en que la llegada al reino de miembros del clero y de la nobleza vinculados con los círculos políticos y religiosos catalano-aragoneses pudo haber sido el principal impulso para la nueva arquitectura. Desde hace décadas se insiste en la importancia que en este proceso tuvo la diócesis de Palencia, a donde llegaron a lo largo del siglo XI una serie de obispos formados en los entornos monásticos del oriente peninsular, llamados a reformar las costumbres del clero local desde la cátedra palentina (LOMAX, 1982, p. 191-197) impulsando tanto los dictámenes del concilio de Coyanza de 1055 como la benedictización del monacato.

Una muestra clara de este enfoque historiográfico es la hipótesis que considera que la cercanía a Perazancas de importantes fábricas benedictinas como San Martín de Frómista, San Zoilo de Carrión de los Condes y San Isidro de Dueñas pudo haber ayudado a crear un contexto óptimo para la aparición de estéticas lombardistas en este templo (HUERTA HUERTA, 2002, p. 823 ${ }^{10}$. Un segundo ejemplo clásico de esta línea interpretativa es la teoría que

\footnotetext{
${ }^{9}$ Siempre debe tenerse en cuenta además lo mucho que pueda haberse perdido.

${ }^{10}$ Se debe ser muy prudente ante estas afirmaciones ya que lo lombardista convive en los reinos occidentales con la estética del románico pleno, llamada a pervivir. Lo que hoy conocemos de las grandes instituciones cluniacenses castellanas no nos permite establecer una relación directa entre la arquitectura lombardista y la benedictización del monacato (Sobre la arquitectura cluniacense hispana véase SENRA GABRIEL Y GALÁN, 2011, p. 335-366). En el siglo XI hispano conviven las reformas eclesiásticas con formulaciones arquitectónicas del primer románico, del románico pleno y con otras pervivencias de la arquitectura altomedieval, sin que sea sencillo establecer unas coordenadas claras entre las políticas reformistas y las diversas opciones en arquitectura.
} 
considera que las formas lombardistas en Urueña pueden ser debidas a la conexión catalana que supuso el matrimonio en 1095 entre María Pérez, hija de Pedro Ansúrez, con Ermengol V, conde de Urgell (HERAS GARCÍA, 1966, 47-52). Estos ejemplos muestran que, para algunos investigadores, la presencia de élites nobiliarias venidas de fuera del reino, de una parte, y el proceso de benedictización de la vida monástica, de la otra, pudieron ayudar a crear un ecosistema propicio para la llegada de una estética ajena a los reinos occidentales.

Para el caso gallego se han esbozado también teorías similares para la recepción de las formas lombardistas en las fábricas estudiadas. Desde un punto de vista general, los aires renovadores y el diálogo con realidades culturales foráneas tienen su epicentro en la elevación de la fábrica románica de la catedral de Santiago de Compostela, iniciada entre 1075 y 1078. La presencia de obispos de origen cluniacense como Dalmacio, de talleres de filiación navarroaragonesa activos en el entorno de la cabecera o, incluso, el posible papel de intermediario del depuesto obispo Diego Peláez desde el exilio oscense (CASTIÑEIRAS GONZÁLEZ, 2007, p. 126), son solo una pequeña muestra de la importancia que tuvo la apertura a nuevas realidades geográficas y culturales a la hora de renovar el lenguaje edilicio en el territorio gallego a finales del siglo XI. Sin embargo en la iglesia compostelana, a tenor de lo conservado, no se empleó el lenguaje lombardista, lo que invita a no sobrestimar el entorno cultural compostelano en este proceso. En Santiago, la internacionalización cristalizó en la asunción del lenguaje del románico pleno, pero parece que no así en el de la arquitectura lombardista.

En el estudio del origen de esta tradición constructiva del primer románico en paralelo a las estéticas compostelanas se ha valorado especialmente la figura del obispo Gonzalo de Mondoñedo, presente en la sede desde 1077 hasta 1112. El prelado, formado en el monasterio de Sahagún, fue un religioso activo en las polémicas intelectuales de su tiempo y ha querido verse en su llegada a la cátedra mindoniense un punto de inflexión renovador en el seno del clero gallego que, además, sirvió de acicate para la renovación monumental románica. Castiñeiras González ha apuntado la posibilidad de que el obispo hubiese conocido de primera mano algunas de las corrientes renovadoras en la arquitectura castellanoleonesa, gracias a su participación en los concilios de Burgos (1080) y Husillos (1088). Para el citado investigador, la asistencia a este último concilio en tierras palentinas pudo permitirle conocer, al menos, la primitiva catedral de Palencia (CASTIÑEIRAS GONZÁLEZ, 1999, p. 300). Un último 
aspecto por destacar en la biografía del obispo es su asistencia en el año 1088 a la consagración de San Isidro de Callobre, cercana a San Xoán de Vilanova. La presencia de Gonzalo de Mondoñedo en la comarca vincula a las dos edificaciones lombardistas gallegas y pudo ser el nexo que permitiese la aparición de estas formas en Vilanova (CASTIÑEIRAS GONZÁLEZ, 2004, p. 604-605). La ausencia de otros datos documentales imposibilita ir más allá.

Junto con el posible papel de algunos prelados, el paulatino proceso de benedictización de la vida monástica de Galicia también puede estar en la génesis de algunas de las experiencias lombardistas. Es de enorme interés el caso de San Antoíño de Toques ya que en el documento de donación del rey García del año 1067 se hace mención expresa a la observancia benedictina por primera vez en la documentación de la Galicia medieval (ANDRADE CERNADAS, 2015, p. 98). A la luz de estas informaciones podría parecer clara la relación entre renovación monumental y reforma de la observancia, pero la precocidad de Toques de cara a asumir la regla de san Benito no se traduce en una arquitectura excesivamente renovadora. Como se ha señalado con anterioridad, existen arcuaciones ciegas en el ábside de la iglesia monástica, pero estas se encuentran lejos de los arquitos lombardistas más canónicos y, además, la planimetría que asume la iglesia es absolutamente conservadora. Es decir, la renovación de la vida en común bajo la regla benedictina no supuso una reforma absoluta de los conceptos arquitectónicos, lo que impide establecer una relación causa-efecto clara.

Un último factor que pudo influir en la recepción de la arquitectura lombardista en San Xoán de Vilanova es la incorporación a Cluny del cercano monasterio de San Martiño de Xuvia en $1113^{11}$. La adhesión debió fraguarse ya a finales del siglo $\mathrm{XI}$, como parece deducirse del hecho de que Xuvia se mencione tanto en la visita que el camerario cluniacense Dalmacio realizó a los monasterios españoles cluniacenses, entre 1090 y 1094, como en la Bula que Pascual II dirige al abad Hugo de Cluny en 1100. La donación definitiva a Cluny, producida en diciembre de 1113, es otorgada por Pedro Froilaz y sus hermanas Munina y Visclavara, con la aprobación de los obispos Diego Gelmírez de Compostela y Munio de Mondoñedo (ANDRADE

\footnotetext{
${ }^{11}$ Es el segundo priorato gallego en incorporarse a la red de la abadía borgoñona tras San Vicente de Pombeiro, en el sur de Lugo, que se había incorporado previamente en 1109.
} 
CERNADAS, 2015, p. 106) ${ }^{12}$. La inclusión de Xuvia en el entramado cluniacense es en sí misma una prueba de apertura de las instituciones galaicas, pero además en el documento de donación se recoge que el prior debe ser siempre un monje de Cluny, lo que atestigua la llegada al noroeste no solo de corrientes de pensamiento foráneas, sino directamente de individuos de fuera del reino venidos a ocupar lugares de poder.

Esta nueva realidad cultural cluniacense en el área del noreste coruñés a inicios del siglo XII pudo ser un catalizador para la llegada de nuevas formas arquitectónicas y quizá, como ya se ha planteado para el caso de Perazancas, la benedictización pueda estar tras la elección del lenguaje lombardista en las iglesias gallegas. La hipótesis es plausible, pero no está exenta de problemas, ya que no existe un consenso claro a la hora de proponer una datación para la iglesia que permitiese relacionar los hechos políticos con los artísticos. Además, la fábrica románica de Xuvia se conserva, pero en ella se desarrolla un lenguaje del románico pleno de raigambre internacional y no una arquitectura lombardista.

A pesar de todos estos inconvenientes, existen datos documentales y epigráficos que invitan, al menos, a la reflexión. A lo largo del siglo XII se produjeron diversas donaciones a Xuvia que tradicionalmente se han vinculado con la elevación de la fábrica del románico pleno, pero ya desde mediados del siglo XI el monasterio se beneficia de la protección de los Traba, hasta el punto de que en el año 1086 el conde Froila Bermúdez solicita ser enterrado en San Martiño de Xuvia (LÓPEZ FERREIRO, 1983, p. 322, nota 1). No cabe duda de que el favor nobiliario durante el siglo XII y la inclusión en la red cluniacense propiciaron el contexto para la elevación de la iglesia actual, pero teniendo presentes documentos como el del año 1086 parece razonable plantear la existencia de una fábrica anterior financiada gracias a estas dádivas, que se ubicase cronológicamente entre una desconocida construcción altomedieval y la iglesia plenorrománica. Además, en el exterior del muro sur de la nave se encuentra una inscripción alusiva al año 1111 que podría hacer referencia a la existencia de obras -de inicio o finalización- en esa fecha. Un último documento importante para la historia edilicia de Xuvia se fecha en el año 1190 y, en él, el obispo Rabinato de Mondoñedo concede indulgencias a

\footnotetext{
12 Pedro Froilaz, conde de Traba, es una de las figuras más importantes de la nobleza gallega de su tiempo. Fue aliado fundamental del conde de Galicia Raimundo de Borgoña, ejerció de ayo de Alfonso VII y desde 1107 ejerció, él mismo, como conde de Galicia. Cierta parte de la historiografía lo ha considerado hermano del propio Gonzalo de Mondoñedo, pero es esta una cuestión sobre la que no existe consenso (FLETCHER, 1992, p. 62-63).
} 
quienes ayuden en la reconstrucción de la iglesia (MONTERO DÍAZ, 1935, p. 108) ${ }^{13}$ lo que vendría a probar que se está trabajando en la fábrica del románico pleno en fechas muy tardías.

Como se ha visto, la realidad monumental de Xuvia entre la Alta Edad Media y el románico es altamente compleja y no es sencillo establecer secuencias crono-constructivas claras. Sin embargo, a la luz de los datos documentales y epigráficos parece que existió una secuencia de obras anterior a la adscripción cluniacense y, al menos, una segunda campaña a finales del siglo XII. Una horquilla cronológica tan amplia que va desde finales del siglo XI hasta después de 1190 no parece razonable para una única fábrica de estas características ${ }^{14}$, de modo que la hipótesis de una iglesia románica previa es factible. Por ello, de existir una edificación iniciada a finales del siglo XI-coincidiendo con los primeros contactos con el mundo benedictino- y finalizada con posterioridad a la llegada de los primeros monjes cluniacenses tras 1114, ¿no sería posible la existencia de una iglesia de Xuvia con un lenguaje del primer románico que pudiese ser un eslabón entre los ábsides con arquitos ciegos de San Martiño de Mondoñedo y de San Xoán de Vilanova?

Por supuesto, la cuestión es irresoluble y se mantiene como un ejercicio de índole intelectual, pero la lectura de las fuentes sí indica un alto interés en la región por parte del triángulo de poder conformado por el obispado de Mondoñedo, el monacato cluniacense y la familia de los Traba. No podemos saber si existieron edificios del primer románico en Xuvia o en otras iglesias de la región, pero sí puede afirmarse que el clima político y religioso era, como en tierras palentinas, el adecuado para la llegada de formas renovadoras para la arquitectura y que el monasterio de Xuvia se encontraba en el centro de los intereses de estas élites eclesiásticas y nobiliares. La proximidad de San Xoán de Vilanova a este centro monástico posibilita, por lo tanto, que la renovación monumental de la una pueda vincularse con las reformas religiosas -y quizás constructivas- de la otra.

\footnotetext{
${ }^{13}$ Castillo López y algunos autores después de él hacen referencia a una donación del año 1137 en la que se alude a una "reedificación". Lamentablemente no hemos podido localizar dicho documento de modo que lo hacemos notar.

14 Recuérdese que una campaña como la compostelana, enormemente más ambiciosa, se prolongó desde 1075/78 hasta 1211 y, en gran medida, por la casuística concreta -e inusual- del desnivel del solar en el que se edificó. Por lo tanto, no parece razonable que la elevación de una iglesia menor como Xuvia se dilatase tanto en el tiempo.
} 
Es este un enfoque no ponderado hasta la fecha, pero la entidad y cercanía del monasterio y la importancia de la inclusión de Xuvia en la red monacal cluniacense -en tanto que fenómeno renovador e internacionalizante- hacen que esta hipótesis sea plausible y puede abrir nuevos caminos a la hora de comprender el fenómeno lombardista en el noroeste de la Península Ibérica.

\section{Conclusión}

Con el presente trabajo se ha propuesto un actualizado estado de la cuestión acerca de una de las iglesias pioneras del románico gallego que es, además, una de las pocas muestras de la arquitectura lombardista en el noroeste peninsular. Partiendo de la problemática terminológica y de los límites geográficos y temporales para estos modelos arquitectónicos, se ha procurado analizar su fábrica desde la relación que las elecciones formales puedan tener con el contexto cultural en el que se gestaron. De manera muy resumida, son dos las grandes conclusiones que pueden extraerse de este estudio.

En primer lugar, no es posible establecer fórmulas unidireccionales entre los fenómenos de renovación religiosa o de mecenazgo político y las elecciones estéticas y edilicias. En el cuadrante noroeste peninsular de finales del siglo XI e inicios del siglo XII conviven formas heredadas del prerrománico con nuevas soluciones lombardistas o del románico pleno, sin que podamos adjudicarlas a procesos culturales concretos. Solo en tierras gallegas, en la renovada Compostela se opta por un lenguaje de ascendencia ultrapirenaica en paralelo al primer románico de Mondoñedo o Vilanova, mientras que la benedictina iglesia de Toques emparenta con propuestas de la Alta Edad Media. La permeabilidad parece la tónica imperante y cada caso debe analizarse de manera pormenorizada.

A pesar de ello y, en segundo lugar, parece claro que la transición al románico en el territorio se produjo de la mano de la llegada de corrientes culturales foráneas que se imbricaron con la realidad sociopolítica local. La ausencia de documentación para Vilanova hacía imposible el análisis del contexto concreto para el estudio de su fábrica, pero la apertura del foco investigador puede ayudar a comprender mejor el entorno que propició la aparición de nuevas estéticas, como demuestran los estudios sobre el mecenazgo del obispo Gonzalo y la renovación de la primitiva catedral de Mondoñedo. En este sentido, está pendiente de valoración en toda su profundidad el papel jugado por la casa de Traba y por el monasterio cluniacense de Xuvia en la recepción de las formas de la arquitectura lombardista. Es cierto 
que la carencia de vestigios materiales es una losa para la investigación, pero esta problemática puede suplirse mediante el estudio de las relaciones del linaje de los condes de Traba y de los abades de Xuvia con agentes foráneos de cara a comprender las complejas redes de intercambio cultural que facilitaron la aparición del lenguaje constructivo del primer románico. En estas líneas se ha pretendido afianzar esta vía que, en futuras investigaciones, podrá ayudar al mayor conocimiento del contexto de Vilanova y de la cuestión lombardista en un territorio de Galicia en el que, como se señaló al inicio de este artículo, esta arquitectura convive "oculta" tras las exitosas formulaciones compostelanas.

\section{REFERENCIAS BIBLIOGRÁFICAS}

ANDRADE CERNADAS, José Miguel. La introducción de Cluny en Galicia: ritmos y resistencias. Studia Monastica. Barcelona, vol. 57, fasc. 1, pp. 91-111, 2015.

BANGO TORVISO, Isidro Gonzalo. Galicia Románica. Vigo: Galaxia, 1987.

BANGO TORVISO, Isidro Gonzalo. Arquitectura románica en Galicia. Desde los orígenes hasta 1168. In: VALLE PÉREZ, José Carlos; RODRIGUES, Jorge (coords). El Arte Románico en Galicia y Portugal. A Coruña: Fundación Pedro Barrié de la Maza, pp. 12-29, 2001.

CAMPS, Jordi, FREIXAS Pere (dirs.). Simposi Internacional. Els comacini i l'arquitectura románica a Catalunya. Universitat de Girona, 25 de noviembre. Museu Nacional d'Art de Catalunya, 26 noviembre 2005. Barcelona: MNAC, 2010.

CARRILLO LISTA, Ma del Pilar. Arte románico en el Golfo Ártabro y el oriente coruñés. Santiago de Compostela: Tesis doctoral inédita, 2005.

CASTILLO LÓPEZ, Ángel del. Inventario de la Riqueza Monumental y Artística de Galicia. A Coruña: Fundación Pedro Barrié de la Maza.

CHAMOSO LAMAS, Manuel. Desconocida muestra arquitectónica del primer románico en Galicia. Homenaje a D. J. Esteban Uranga. Pamplona: Aranzadi, 1971.

CHAMOSO LAMAS, Manuel. Nuevas aportaciones al conocimiento de las primeras manifestaciones de la arquitectura románica en Galicia, surgidas de la peregrinación a Compostela. Príncipe de Viana. Pamplona, año no 34, no 132-133, pp. 215-222, 1973.

CHAMOSO LAMAS, Manuel; González, Victoriano; Regal, Bernardo. Galicia. La España Románica. Madrid: Ediciones Encuentro, 1979.

CASTIÑEIRAS GONZÁLEZ, Manuel Antonio. Arte del pellegrinaggio e primo romanico: le scelte artistiche nella Galizia dell'XI secolo. In: QUINTAVALLE Arturo Carlo (coord.). Medioevo. Arte lombarda. Atti del convegno internazionale di studi (Parma, 26-29 settembre 2001). Milán: Mondadori Electa, p. 602-613, 2004.

CASTIÑEIRAS GONZÁLEZ Manuel Antonio. San Martiño de Mondoñedo (Foz) Revisitado. In SINGUL LORENZO Francisco (dir.). Rudesindus. A terra e o templo. Santiago de Compostela: Consellería de Innovación e Industria. S.A. de Xestión do Plan Xacobeo, pp. 118-137, 2007. 
ESTEBAN LORENTE, Juan Francisco; GALTIER MARTí, Fernando; GARCÍA GUATAS, Manuel. El nacimiento del arte románico en Aragón. Zaragoza: Caja de Ahorros de la Inmaculada de Aragón (CAI), 1982.

FLETCHER Richard A. A Vida e o tempo de Diego Xelmírez. Vigo: Galaxia, 1992.

FLÓREZ, Enrique. España sagrada. Teatro geográfico-histórico de la Iglesia de España. Tomo XVIII, De las Iglesias Britoniense, y Dumiense, incluídas en la actual de Mondoñedo. Copia Digital de la edición de 1764. Valladolid: Junta de Castilla y León. Consejería de Cultura y Turismo, 2009-2010.

HERAS GARCÍA, Felipe. Arquitectura románica en la provincia de Valladolid. Valladolid: Imprenta Provincial, pp. 47-52, 1966.

HOYO, Jerónimo del. Memorias del Arzobispado de Santiago. Facsímil de la Edición de 1607. Edición de RODRÍGUEZ GONZÁLEZ, Ángel y VARELA JÁCOME, Benito. Santiago de Compostela: Porto, s.f.

HUERTA HUERTA, Pedro Luis. Voz: Perazancas de Ojeda. Ermita de San Pelayo. In García Guinea, Miguel Angel; Pérez González, José María (dirs.); Rodríguez Montañés, José Manuel (coord.). Enciclopedia del románico en Castilla y León. Palencia. Aguilar de Campoo: Fundación Santa María la Real, Centro de Estudios del Románico, Vol. II, pp. 819-828.

LOMAX, Derek W. Catalans in the Leonese empire. Bolletin of Hispanic Studies. Liverpool, vol. LIX, p. 191-197, 1982.

LÓPEZ FERREIRO, Antonio. Historia de la Santa A. M. Iglesia de Santiago de Compostela. T. III. Edición Facsímil. Santiago de Compostela: Edicións Sálvora, 1983.

LUCAS ÁlVAREZ, Manuel. San Paio de Antealtares, Soandres y Toques: tres monasterios medievales gallegos. Sada: Ediciós do Castro, 2001.

MONTERO DÍAZ, Santiago. La colección diplomática de San Martín de Jubia (979-1199). Santiago de Compostela: El Eco Franciscano, 1935.

NÚÑEZ RODRÍGUEZ, Manuel. Algunas reflexiones sobre el románico rural gallego. Anuario Brigantino, Betanzos, № 6, pp. 113-120, 1983.

PORTER, Arthur Kingsley. Lombard Architecture. New Haven: Yale University Press, 1915-1917.

POUSA FERNÁNDEZ, Ana María. Voz: Vilanova. Iglesia de San Xoán. In: PÉREZ GONZÁLEZ, José María (dir.); VALLE PÉREZ, José Carlos (coord.). Enciclopedia del románico en Galicia. A Coruña. Aguilar de Campoo: Fundación Santa María la Real, Centro de Estudios del Románico, Vol. II, pp. 1263-1270.

PUIG I CADAFALCH, Josep. La geografia i els orígens del primer art romànic. Barcelona: Institut d'estudis catalans, 1930.

QUINTAVALLE Arturo Carlo (coord.). Medioevo. Arte lombarda. Atti del convegno internazionale di studi (Parma, 26-29 settembre 2001). Milán: Mondadori Electa.

SENRA GABRIEL Y GALÁN, Jose Luis. Las grandes instituciones cluniacenses hispanas bajo el reinado de Alfonso VI. Anales de Historia del Arte. Madrid, Volumen Extraordinario (2), pp. 335-366.

SORALUCE BLOND, José Ramón (coord.). Arquitectura románica de La Coruña: Faro-Mariñas-Eume. A Coruña: C.O.A.G., 1983. 
VALLE PÉREZ, José Carlos. Las cornisas sobre arquitos en la arquitectura románica del noroeste de la Península. Compostellanum, Santiago de Compostela, Vol. XXIX, pp. 291-356, 1984.

YZQUIERDO PERRÍN, Ramón. De arte et architectura. San Martín de Mondoñedo. Lugo: Diputación Provincial de Lugo. Servicio de Publicaciones, 1994.

YZQUIERDO PERRÍN, Ramón. Galicia. Arte. Arte Medieval (I). T. X, A Coruña: Hércules de Ediciones S. A., 1995.

YZQUIERDO PERRÍN, Ramón. Diego Gelmírez y los inicios del románico en Galicia. In: LÓPEZ ALSINA, Fernando; MONTEAGUDO, Henrique; VILLARES, Ramón; YZQUIERDO PERRÍN, Ramón (coords.). $O$ século de Diego Xelmírez. Santiago de Compostela: Consello da Cultura Galega, pp. 207-244, 2013. 